\title{
URINARY METANEPHRINE LEVELS CAN BE SPURIOUS \\ IN DIAGNOSIS OF PATIENTS WITH PHEOCHROMOCYTOMA: \\ PRELIMINARY RESULTS FROM A SINGLE CENTER
}

\section{Oya Topaloglu ${ }^{1}$, Husniye Baser ${ }^{2}$, Cevdet Aydin ${ }^{1}$, Ahmet Dirikoc ${ }^{1}$, Reyhan Ersoy ${ }^{1}$, Ozcan Erel ${ }^{3}$, Bekir Cakir ${ }^{1}$}

1 Yildirim Beyazit University Faculty of Medicine, Department of Endocrinology and Metabolism, Ankara, Turkey

${ }^{2}$ Atatürk Education and Research Hospital, Department of Endocrinology and Metabolism, Ankara, Turkey

${ }^{3}$ Yildirim Beyazit University Faculty of Medicine, Department of Biochemistry, Ankara, Turkey

\section{INTRODUCTION}

$>$ Pheochromocytomas (PHEO) are diagnosed with classic findings and symptoms but biochemical confirmation must be made. Either urinary or plasma chatecholamines and metanephrines can be used for biochemical evaluation. Normal values rule out the diagnosis, whereas four fold increase above the upper limit of normal confirm the diagnosis. But value of borderline or less than 4 fold elevations in the diagnosis is not clear. We aimed to determine the urinary fractionated metanephrine and catecholamine levels in patients with PHEO.

\section{MATERIAL AND METHODS}

$>$ Thirteen patients with final diagnosis of PHEO (PHEOgroup) and 10 patients (non-PHEO -group) who underwent to adrenalectomy and finally diagnosed as benign neoplasm (6 adenomas, 3 cysts, 1 hyperplasia) were evaluated retrospectively. Urinary metanephrines were evaluated by high- performance liquid chromatography (HPLC).

\section{RESULTS}

> In PHEO-group urinary metanephrines were as follows: 3 (25\%) had borderline elevations, 9 (75\%) had normal values, however $1(10 \%)$ had borderline elevation, $1(10 \%)$ had 6 fold elevations, 8 (80\%) had normal values in non-PHEOgroup. The difference was evaluated as statistically insignificant $(\mathrm{p}=0.19)$. Normetanephrine values were as follows: borderline elevation in $5(41.7 \%), 2$ fold elevation in $1(8.3 \%), 6$ fold elevation in $1(8.3 \%)$ and normal values in $5(41.7 \%)$ patients in PHEO-group; borderline elevations in $2(20 \%), 2$ fold elevation in $1(10 \%)$, normal values in 7 (70\%) patients in non-PHEO group.
$>$ This was also statistically insignificant $(\mathrm{p}=0.39)$ (Table 1). There were also no significant differences in urinary adrenaline and noradrenaline levels between groups.

Table 1. Levels of the urinary catecholamine metabolites in PHEO-group and non-PHEO group

\begin{tabular}{lccc}
\hline & $\begin{array}{c}\text { PHEO- } \\
\text { group }(\mathbf{n}=\mathbf{1 3})\end{array}$ & $\begin{array}{c}\text { Non-PHEO- } \\
\text { group }(\mathbf{n = 1 0})\end{array}$ & P value \\
\hline $\begin{array}{l}\text { Metanephrine } \\
\text { Normal }\end{array}$ & $3(25 \%)$ & $8(80 \%)$ & 0.19 \\
$\begin{array}{l}\text { Borderline elevation } \\
\text { 6 fold elevation }\end{array}$ & $9(75 \%)$ & $1(10 \%)$ & \\
& - & $1(10 \%)$ & \\
$\begin{array}{l}\text { Normetanephrine } \\
\text { Normal }\end{array}$ & $5(41.7 \%)$ & $7(70 \%)$ & \\
$\begin{array}{l}\text { Borderline elevation } \\
\text { 2 fold elevation }\end{array}$ & $5(41.7 \%)$ & $2(20 \%)$ & \\
6 fold elevation & $1(8.3 \%)$ & $1(10 \%)$ & \\
& $1(8.3 \%)$ & - & \\
& & & \\
\end{tabular}

\section{CONCLUSION}

$>$ Patients with borderline -elevated urinary metanephrine levels can also have PHEO. In patients with adrenal incidentalomas (AI) who are candidate for surgery and have borderline elevated metanephrines should be evaluated carefully.

$>$ In this group of patients, we advocate either routine preoperative preparation as patients possessing PHEO or further diagnostic tests in order to prevent the serious complications. 